\title{
Review of Aflatoxin Reduction Potential of Antioxidants
}

\author{
Esayas Abrha Zerihun Asefa \\ Ethiopian Institute of Agricultural Research, Holetta Agricultural Research Centre, \\ PO Box 2003, Addis Ababa, Ethiopia
}

\begin{abstract}
Pests and diseases are prevalent on food commodities such as maize, sorghum, millet, and cassava in the field and during storage. Toxigenic fungi such as Aspergillus, Fusarium, and Penicillium create mycotoxins, which are secondary metabolites. Both people and animals are susceptible to their mutagenic, teratogenic, and carcinogenic effects. Aspergillus flavus and Aspergillus parasitic generate the most potent mycotoxins, which are found in agricultural products such as peanuts, maize grains, cereals, and animal feed. The most common incidence and stability of these mycotoxins to physical and chemical variables during food and feed processing offer substantial health risks to humans and animals. As a result, the best way to deal with this condition is to use both natural and synthetic detoxification methods. The goal of this review is to look at how natural and synthetic chemical approaches can be used to control aflatoxins contamination and how they can be reduced. Antioxidants are compounds that help prevent or reduce cell damage caused by free radicals, which are unstable molecules produced by the body in response to environmental and other stresses. Oxidative stress, which causes DNA, protein, and lipid damage at the cell level, is one of AFB1's harmful mechanisms. Antioxidants have been used as food additives to defend against oxidative deterioration since they are known to prevent fungal formation. Among the various options, antioxidants are one of the control methods of mycotoxin and which are regulated as dietary supplements and food consumption components. To reduce the effect of toxicity, the best way to prevent aflatoxin prevalence in agricultural products is to make suitable harvesting and storage conditions, but if that is not possible, it is better to eat fermented foods (yogurt or dairy drinks) or take probiotics, which are available as capsules, tablets, or powders.
\end{abstract}

Keywords: Aflatoxin; Antioxidants; Mycotoxin; Fermented-food; Toxicity.

DOI: $10.7176 / \mathrm{CPER} / 64-02$

Publication date: January $31^{\text {st }} 2022$

\section{Introduction}

Many pests and diseases are prevalent on food commodities such as maize, sorghum, millet, and cassava in the field and during storage. Stored and processed food products carry a wide range of microorganisms like bacteria, yeasts and fungi (Lacey \& Magan, 1991). Fungal infestation can lead to discoloration, production of off-odors and can result in mycotoxins (Magan et al., 2003). Mycotoxins are secondary metabolites produced by fungi that are toxic to humans and animals (Gnonlonfin et al., 2013). They are produced at both field and storage levels. By Fusarium and Penicillium species (Miller, 1995). Mycotoxins production by fungi is influenced by abiotic and biotic factors.

Abiotic factors include environmental factors such as temperature, water availability and gas composition (Magan et al., 2003). The nature of the substrate, its inherent moisture content, and insect infestation are all biotic factors that can lead to an increase in fungal population and, as a result, the formation of mycotoxins. (Dowd, 2003). Penicillium species produce ochratoxins, citrinin, patulin (Pitt, 2000). Aspergillus species produce (principally) aflatoxins, citrinin, patulin (Gokmen et al., 2005). Among the 300 reported mycotoxins, AFB1 is the most dangerous one. Aflatoxins were discovered about 40 years ago after the devastating loss of poultry in England (Probst et al., 2007)

It's synthesized by at least 15 species belonging to the Flavin section of the Aspergillus genus. in sub-Saharan Africa, Latin America and Asia the exposure levels of mycotoxins (aflatoxins), are increased through contaminated commodities (J. I. Pitt et al., 2012). In Africa work on aflatoxin has focused on applied research with very little basic research and even less on the effect of environmental conditions (Gnonlonfin et al., 2013). Scientists have indicated that antioxidant obtained from daily diets can scavenge the reactive oxygen species. They cause the inhibition of peroxidation, mopping up of free oxygen radicals and breakage of peroxidation chain reactions on the formulation of aflatoxins (Sharma, 2013).

\section{Aflatoxin}

Aflatoxins are the most important mycotoxins with regard to occurrence, toxicity, and impact on human health and trade. Fungi that produce aflatoxin are found all over the world and can thrive in a variety of environments. (Holmquist et al., 1983). Aflatoxins have been found in cereal grains, fermented beverages, milk, cheese, meat, nut goods, fruit juices, and a wide variety of other agricultural products. (Bullerman, 1986). The presence of aflatoxins or toxigenic fungi in foods presents a potential hazard to human and animal health (Abdel-Wahhab \& 
Aly, 2005). The four major aflatoxins commonly isolated from foods and feeds are aflatoxins B1, B2, G1, and G2.<smiles>COc1cc2c(c3oc(=O)c4c(c13)CCC4=O)[C@H]1C=CO[C@H]2O1</smiles>

Aflatoxin $\mathrm{B}_{1}$<smiles>COc1cc2c(c3oc(=O)c4c(c13)CCC4=O)C1CCOC1O2</smiles>

Aflatoxin $\mathrm{B}_{2}$<smiles>COc1cc2c(c3oc(=O)c4c(c13)CCOC4=O)[C@H]1C=CO[C@H]2O1</smiles>

Aflatoxin $\mathrm{G}_{1}$<smiles>COc1cc2c(c3oc(=O)c4c(c13)CCOC4=O)[C@H]1CCO[C@H]2O1</smiles>

Aflatoxin $\mathrm{G}_{2}$

Figure 1. Chemical structures of aflatoxins

Aflatoxins have been shown to be toxigenic, carcinogenic, mutagenic, and teratogenic to different species of animals (Abdel - Wahhab et al., 1999). In animals the toxin is processed through a number of competing pathways (Eaton \& Groopman, 2013).

\section{Aflatoxin B1}

Aflatoxin B1 is a fungal toxin produced by a species of Aspergillus. It's a common dietary contaminant all over the world, mostly in the hot and humid climate regions (Organization, 2002). The toxic and carcinogenic effects of AFB1 are intimately linked with its biotransformation (Williams et al., 2004). The active intermediate, AFB1exo-8, 9-epoxide, can bind with DNA to form the predominant trans-8, 9-dihydro-8-(N7-guanyl)-9-hydroxy-AFB1 (Halver, 1965). AFB1 toxicity in different species varies as per the age, gender, specific sensitivity, dosage, and duration of toxin exposure. AFB1 toxicity in livestock and human beings is a major economic and health concern.

\section{Aflatoxin M1}

Aflatoxins M1 are hydroxylated metabolites of aflatoxin B1and are produced in milk-producing animals (Lanyasunya et al., 2005). The presence of AFM1 in milk and dairy products is thought to pose some sanitary concerns to mammals, including humans. The presence of AFM1 in infected milk or contaminated consumables is linked to the presence of AFB1 (Prandini et al., 2009). The levels of AFM1 in milk and dairy products were connected to the climate of each geographical area as well as changes in the dairy cattle feeding strategy (Mahmoudi et al., 2014). As a result, AFs in both animal feed and milk should be checked on a regular basis in order to reduce the level of AFM1 in milk (Mahmoudi et al., 2014).

\section{Aflatoxin Biosynthesis}

Various studies have determined that aflatoxins are synthesized in two stages from malonyl CoA. First with the formation of hexanoyl CoA, followed by formation of a decaketide anthraquinone (Minto and Townsend, 1997). Then a series of highly organized oxidation-reduction reactions allows formation of aflatoxin (Nesci et al., 2016). But, it's elucidated in the last decade at a molecular level. Several enzymes are also involved in aflatoxin biosynthesis such as reductase and cyclase (Bhatnagar et al., 1992). Whereas the independent reactions and formation of different chemical precursors are catalyzed by common enzyme systems (Anderson et al., 1990). 


\section{Aflatoxicosis}

Aflatoxin poisoning is the outcome of consuming aflatoxins. Aflatoxicosis can be divided into two types: 1) Acute severe intoxication, which causes direct liver damage and can lead to illness or death. 2) Chronic sub-symptomatic exposure is the second. Adult people have a great tolerance for aflatoxin, and children are frequently the ones that die in recorded acute poisonings. (Eaton \& Groopman, 2013). Baumgartner et al., 2005 demonstrated that males were more likely to die from Aflatoxicosis despite eating similar quantities of maize as females. Similarly a higher liver cancer rate has been observed in male, with a ratio of 3.4 males per female cases (Kirk, Bah, \& Montesano, 2006.

\section{Economic Significance of Aflatoxin Contaminations}

Aflatoxin contamination of foods and feeds is a serious worldwide problem (Deepak Bhatnagar et al., 2002). This results either from improper storage of commodities or pre-harvest contamination. But, Because of a reluctance to acknowledge its occurrence, the global scope of pollution is unknown. (Jelinek et al., 1989). However, Aspergillus fungus, as well as their toxins, are found all over the world. They result in considerable agricultural losses, animal sickness and mortality, and immunologically compromised people. (Udomkun et al., 2017).

\section{Health Impact of Aflatoxins}

The toxic effect of mycotoxins in humans and animals depends on a number of factors including intake levels, duration of exposure, toxin species, metabolism, and defense mechanisms. In humans and/or animals, eating mycotoxin-contaminated food causes neurotoxic, immune-suppressive, teratogenic, mutagenic, and carcinogenic effects. Induction of liver cancer and immune system suppression are two of aflatoxin's significant side effects. (Jackson \& Groopman, 1999). Several epidemiological studies indicated that AFB1 intake is associated with a high incidence of primary liver cancer in human in Africa and Asia (Peers et al., 1976). Human epidemiology and experimental animal studies have also provided the statistical association to suggest that aflatoxins are risk factors for human liver cancer (Groopman et al., 1992).

The degree to which Aflatoxins contribute to liver cancer will be influenced by a number of human health factors, including hepatitis B virus infection, nutritional status, and age. Higher aflatoxin levels have been found in the blood, urine and livers of children with symptoms of nutritional deficiencies. Aflatoxin-positive kwashiorkor children had considerably worse edema, had more infections, had lower hemoglobin levels, and spent more time in the hospital than aflatoxin-negative kwashiorkor children. (Adhikari et al., 1994). As (Uriah et al., 2001) observed Aflatoxin levels in blood and sperm ranged from 700 to $1393 \mathrm{ng} / \mathrm{mL}$, suggesting that it could be linked to infertility. and 60 to $148 \mathrm{ng} / \mathrm{mL}$, in infertile and fertile Nigerian men, respectively.

Aflatoxins are hepato-carcinogens and have been classified as class 1 human carcinogen (Organization \& Cancer, 1993). Hepatitis B can act synergistically with aflatoxins to increase the risk of hepatocellular carcinoma (P. Turner et al., 2000). Turner et al., 2002, reported a positive association between diets contaminated with aflatoxins and high incidence of liver cancer. Hepatocellular carcinoma (HCC) is the most common type of primary liver cancer and accounts for around $70 \%$ of all liver cancers (Llovet and Bruix, 2008). The two principal reasons for this $\mathrm{HCC}$ are aflatoxin B1 and infection with the hepatitis B virus. Lethal consumption of AFB1 leads to a potent hepatic carcinogen, in sub lethal leads to chronic toxicity and at low level results in oxidative damage and neoplasia.

\section{Antioxidants}

At low concentration antioxidants delays the oxidation of proteins, carbohydrates, lipids and DNA. The three main categories of antioxidants, which are: 1) first line defence antioxidants which include SOD, CAT, GR, Fe, Cu 2) second line defence antioxidants which include GSH, Vt C, Vt E 3) third line defence antioxidants which include group of enzymes. Chemical processes (antioxidants) can be used to reduce, destruct, or inactivate AF in milk. But, the major drawback of those methods are they reduce the nutritive value and palatability of food products. Reaction time, temperature, and moisture must also be monitored. Toxic byproducts may also be produced (Salminen et al., 2010)

Ammoniation can mitigate the AFM- 1 content in contaminated foods by $79 \%-90 \%$. Ammonia reacts with AFs molecule by breaking oxygen bond, then open lactone ring of the toxin to produce compounds with lower toxicity (Phillips, 1999). Using of $\mathrm{H} 2 \mathrm{O} 2$ at different temperatures has been suggested to detoxify AFs in milk (Jouany, 2007). Boric acid is also utilized to boost tissue antioxidant defenses through an unknown method that may entail oxidative metabolism alterations. (Pawa and Ali, 2006). HSCAC has been the most extensively studied because of its promising aflatoxin-binding capacity and its capacity has augmented when the metals have free of water. 


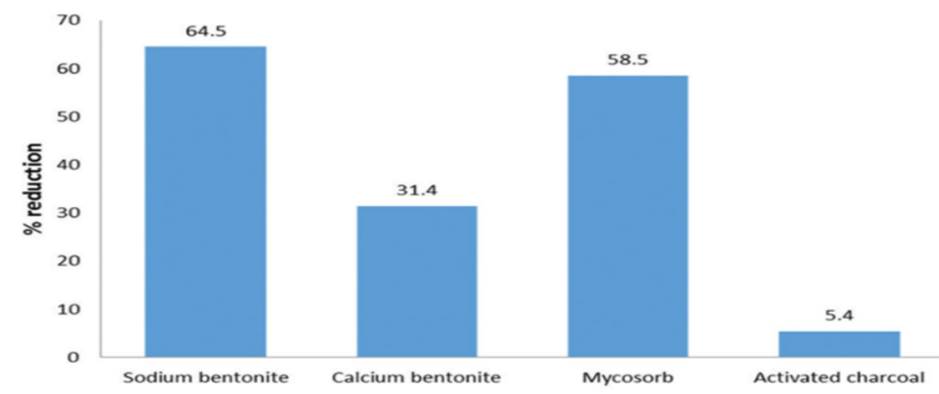

Figure 5 compares effectiveness of some compounds to reduce AF content in milk

Vitamin E can absorb free radicals of oxygen and thus prevent or inhibit the formations of aflatoxins (Traber \& Atkinson, 2007). Time to time the application of synthetic antioxidants has not been appreciated by consumers, food industries, and regulatory authorities. One interesting technic to diminish toxins, especially AFM-1 in foods, is using the plant extracts. As a result, the hunt for natural antioxidants, particularly those of plant origin, has become increasingly important in recent years. (Jayaprakasha \& Rao, 2000). Essential oils from traditionally used plants are acknowledged as a critical component in the development of plant-based preservatives that protect against mold, aflatoxin contamination, and free radical damage (Koci-Tanackov et al., 2012).

Gallic acid has been demonstrated to have a strong inhibitory effect on aflatoxin production. (Mahoney \& Molyneux, 2004). Curcumin is also one of the most extensively studied phytochemicals concerning chemo preventive reduction potential of aflatoxins (Plummer et al., 1999). Ginger phenolics have been studied for its hepatoprotective properties against liver toxicants which is aflatoxins. Tridham it has excellent free radical scavenging effect in rats in which they feed aflatoxin contaminated food (Ravinayagam et al., 2012).

\section{Effect of Antioxidants}

Antioxidants have produced by the living system or they can take through diet supplementation. Scientists are trying to nullify the oxidative effects by providing the antioxidants to the body. Single antioxidants are responsible for protecting a cell's exterior lipid layer. Antioxidants protect cells from free radical damage. Antioxidants are also being looked into as potential treatments for neurological illnesses like Alzheimer's, Parkinson's, and Amyotrophic Lateral Sclerosis. Antioxidants can help the human body cleanse poisons in the liver and other cells, reducing the symptoms of mycotoxicosis.

\section{Chemistry of Free Radicals}

Free radicals are molecules containing one or more unpaired electrons in atomic or molecular orbitals. Formed during a variety of biochemical reactions and cellular functions. Free radicals can cause damage in structural and metabolic components like lipids, proteins, enzymes, carbohydrates and DNA in cells and tissues (Beckman \& Ames, 1998). Free radical-induced damage in oxidative stress has been confirmed as a contributor to the pathogenesis and pathophysiology of many chronic health problems (López-Alarcón and Denicola, 2013).

\section{Methods to Reduce the Harmful Effect of Aflatoxins}

Aflatoxins are controlled mainly based on chemical strategy. However, excessive use of chemical treatments has many undesirable consequences: 1) marked pollution of the environment 2) increase in resistant pathogen 3) presence of chemical residues in food commodities. Some anti-oxidants, such as BHT, BHA or cyst amine, are able to inhibit aflatoxin stimulation (Fanelli et al., 1985). A few studies also reported the inhibiting effect of an isolate of L. edodes on aflatoxin production (Corrado Fanelli et al., 2000). Other chemical preservatives like ammonia, Sodium bisulfite, calcium hydroxide, and Formaldehyde have been found to reduce the level of aflatoxin contamination.

In contaminated milk samples addition of $0.5 \%$ formaldehyde reduced $1.1 \mathrm{ug}$ AFM, to $0.05 \mathrm{pg}$ (Heimbecher et al., 1988). The antioxidant Gallic acid inhibits aflatoxin formation in A. flaVus in a dose-dependent manner. Curcumin has also been shown to be a strong ameliorator of AFB1-mediated oxidative liver damage, preventing AFB1 from converting to hazardous metabolic forms. (Limaye et al., 2018). Ginger could also inhibit the cytotoxicity and hepatotoxicity induced by AFB1 in both in vitro and in vivo. EO was more efficacious as aflatoxin suppressor than fungal growth inhibitor as it caused complete inhibition of aflatoxin secretion by A. flaVus (LHP6 at $1.25 \mathrm{ml} / \mathrm{ml}$.

The high levels of flavonoids and phenolic compounds present in Tridham extracts have also actively, participating in the eliminating of AFB1 metabolite (Sanz et al., 1994). G. indica extract exhibited both antioxidant and antifungal activities (Krishnamurthy et al., 1981). Apart from this any decontamination process must be technically and economically feasible if it is to be applied practically. The FAO's standards for a safe decontamination method (Piva et al., 1995) 1) Remove, destroy, or inactivate aflatoxins 2) Toxic residues should 
not be produced or left in the final products. 3) Destroy fungus spores and mycelium without significantly altering critical technological features.

\section{Conclusions}

Aflatoxins are human carcinogens, actions should focus on the prevention. The prevention of mycotoxin contamination of human foods could have a significant effect on public health especially in low-income countries Antioxidants can aid human body to detoxify toxins in liver and other cells, and consequently decrease the appearance of mycotoxicosis. The above Literature review clearly indicated that aflatoxin contamination becomes highly carcinogenic, mutagenic, changes the food nutrients and presence of harmful products. Therefore the information warns us to take care with aflatoxin contamination and consumption in order not exposed to such carcinogenic, mutagenic and teratogenic disease.

More frequent consumption of foods contaminated with aflatoxin are associated with a higher risk of health problem. Since most of the studies are focused on applied research's, a lack of detailed information on the level of contamination of aflatoxin on foods Future research should focus on these gaps and help develop better assessment tools for aflatoxin contaminated food consumption and their effects on carcinogenic diseases. Strong evidence between the associations of aflatoxin contaminated food consumption with a higher risk of developing carcinogenic disease in humans and animals. Therefore food products should not be exposed to poor post-harvest management, uncontrolled storage conditions

\section{Recommendations}

Factors fundamental to a nation's ability to protect its population from aflatoxin include the following. To begin, a country must have the political will to combat aflatoxin exposure. The majority of countries have signed Codex Alementarius (WHO/FAO documents that deal with food quality in marketed commodities) and agree that their populations should be protected from aflatoxins. They do, however, want to minimize the economic costs of accomplishing this health goal and focus the health resources available on the most pressing issues. They frequently fail to implement these requirements since liver tumors (the most generally recognized health danger) are a minor concern for their populations, and aflatoxin is not on the WHO's list of priority concerns. Second, a country must be able to test food for contamination, as this decides whether or not restrictions can be enforced. Laboratories that can test foods for aflatoxin are extremely rare in developing nations, if they exist at all.

\section{References}

Abdel-Wahhab MA, Aly SE. Antioxidant property of Nigella sativa (black cumin) and Syzygium aromaticum (clove) in rats during Aflatoxicosis. J Appl Toxicol. 2005; 25:218-123.

Abdel-Wahhab, M. A.; Nada, S. A.; Amra, H. A. Effect of aluminosilicate and bentonite on aflatoxin-induced developmental toxicity in rats. J. Appl. Toxicol. 1999, 19, 199-204.

Adhikari, M., Ramjee, G. and Berjark, P. (1994). Aflatoxin, kwarshiorkor and morbidity. Nat.Toxins. 2: 13.

Anderson JA, Chung CH, Cho SH. Versicolorin A hemiacetal, hydroxydihydro- sterigmatocystin and aflatoxin G2 a reductase activity in extracts from Aspergillus parasiticus. Mycopathologia 1990; 111: 39-45.

Atukwase, Abel, Kaaya, Archileo N, \& Muyanja, Charles. (2009). Factors associated with fumonisin contamination of maize in Uganda. Journal of the Science of Food and Agriculture, 89(14), 2393-2398.

Baumgartner, E., Lindblade, K., Gieseker, K., Rogers, S., Kieszak, S., Njapau, H., Schleicher, R., McCoy, L., Misore, A., DeCock, K., Rubin, C. and Slutsker, L. (2005). Aflatoxin investive group. Case-control study of an acute aflatoxicosis outbreak, Kenya, 2004. Environ. Health Pers. 113: 1779-1783.

Beckman and B. N. Ames, "The free radical theory of aging matures," Physiological Reviews, vol. 78, no. 2, pp. 547-581, 1998.

Bhatnagar D, Ehrlich KC, Cleveland TE. Oxidation-reduction reactions in biosynthesis of secondary metabolites. In: Bhatnagar D, Lillehoj EB, Arora DK (Eds.) Handbook of applied mycology: mycotoxins in ecological systems. New York, Marcel Dekker 1992; 255-286.

Bhatnagar D, Yu J, Ehrlich KC. Toxins of filamentous fungi. In: Breitenbach M, Crameri R, Lehrer S (Eds.) Fungal Allergy and Pathogenicity. Chem Immunol. Vol 81, Basel, Karger, 2002: 167-206.

Bullerman, L. B. Mycotoxins and food safety. Food Technol. 1986, 40, 59-66.

Dowd, Patrick F. (2003). Insect management to facilitate preharvest mycotoxin management. Journal of Toxicology: Toxin Reviews, 22(2-3), 327-350.

Eaton, D. L., \& Groopman, J. D. (2013). The toxicology of aflatoxins: human health, veterinary, and agricultural significance: Elsevier.

Eaton D, Ramsdell HS, Neal G. Biotransformation of aflatoxins. In: Eaton D, Groopman JD, eds. The toxicology of aflatoxins: human health, veterinary, and agricultural significance. London: Academic Press, 2013:45-72.

Fanelli C, Fabbri AA, Pieretti S, Finotti E, Passi S (1985) Effect of different antioxidants and free radical scavengers on aflatoxin production. Mycol Res 1:65-69 
Fanelli C, Tasca V, Ricelli A, Reverberi M, Zjalic S, Finotti E, Fabbri AA (2000) Inhibiting effect of medicinal mushroom Lentinus edodes (Berk.) Sing (Agaricomycetideae) on aflatoxin production by Aspergillus parasiticus Speare. Int J Med Mush 2:229-236

Gibb, Herman, Devleesschauwer, Brecht, Bolger, P Michael, Wu, Felicia, Ezendam, Janine, Cliff, Julie, ... Baines, Janis. (2015). Asian Implications of Aflatoxin and Dioxin Foodborne Chemical Exposures Based on World Health Organization Estimates. Asia Pacific Journal of Medical Toxicology, 4(4), 131-133.

Gnonlonfin, Gbemenou Joselin Benoit, Hell, K, Adjovi, Y, Fandohan, P, Koudande, DO, Mensah, GA, ... Brimer, Leon. (2013). A review on aflatoxin contamination and its implications in the developing world: A subSaharan African perspective. Critical reviews in food science and nutrition, 53(4), 349-365.

Gokmen, V., Acar, J. and Sarioðlu, K. (2005). Liquid chromatographic method for the determination of patulin in apple juice using solid-phase extraction. Anal. Chim. Acta 543: 64-69

Groopman, J. D.; Sabbioni, G.; Wild, C. P. Molecular Dosimetry of Aflatoxin Exposures of Human Cancer: Epidemiological, Analytical and Social Consideration; Groopman, J. D., Skipper, P., Eds.; CRC Press: Boca Raton, FL, 1992; pp 302-324.

Heimbecher SK, Jorgensen KV, Price RL. Interactive effects of duration of storage and addition of formaldehyde on levels of aflatoxin M, in milk. J Assoc Offic Anal Chem 1988; 71:285-7.

Holmquist, G. U.; Walker, H. W.; Stahr, H. M. Influence of temperature, pH, water activity and antifungal agents on growth of Aspergillus flaVus and A. parasiticus. J. Food Sci. 1983, 48,

Jackson PE, Groopman JD (1999) Aflatoxin and liver cancer. Baillière's Best Pract Res Clin Gastroenterol 13:545-555

Jayaprakasha, G.K., Jaganmohan Rao, L., 2000. Phenolic constituents from lichen Parmotrema stuppeum (Nyl.) Haleand their antioxidant activity. Z. Naturforsch. 55c, 1018-1022.

Jelinek CF, Pohland AE, Wood GE. Worldwide occurrence of mycotoxins in foods and feeds - an update. J Assoc off Anal Chem 1989; 72: 223-230.

Jouany JP. Methods for preventing, decontaminating and minimizing the toxicity of mycotoxins in feeds. Anim Feed Sci Technol 2007; 137:342-62. Journal of Antimicrobial Agents, vol. 18, no. 1, pp. 85-88, 2001.

Kirk, G. D., Bah, E. and Montesano, R. (2006). Molecular epidemiology of human liver cancer: Insights into etiology, pathogenesis and prevention from The Gambia, West Africa. Carcinogenesis 27: 2070-2082.

Kocić-Tanackov, S., Dimic, G., Tanackov, I., Pejin, D., Mojovi, L., \& Pejin, J. (2012). The inhibitory effect of oregano extract on the growth of Aspergillus spp. and on sterigmatocystin biosynthesis. LWT e Food Science and Technology, 49, 14e20.

Krishnamurthy, N., Lewis, Y.S., Ravindranath, B., 1981. On the structures of garcinol, isogarcinol and camboginol. Tetrahedron Lett. 22, 793-796.

Lacey, J, \& Magan, N. (1991). Fungi in cereal grains: their occurrence and water and temperature relationships. Developments in Food Science (Netherlands).

Lanyasunya, T. P.,Wamae, L.W.,Musa, H. H., Olowofeso, O. and Lokwaleput, I. K. (2005). The risk of mycotoxins contamination of dairy feed and milk on smallholder dairy farms in Kenya. Pakistan J. Nutr. 4: $162-169$

Limaye, A., Yu, R.-C., Chou, C.-C., Liu, J.-R., \& Cheng, K.-C. (2018). Protective and detoxifying effects conferred by dietary selenium and curcumin against AFB1-mediated toxicity in livestock: A review. Toxins, $10(1), 25$.

Llovet, J. M., \& Bruix, J. (2008). Novel advancements in the management of hepatocellular carcinoma in 2008. Journal of hepatology, 48, S20-S37.

López-Alarcón, C., \& Denicola, A. (2013). Evaluating the antioxidant capacity of natural products: A review on chemical and cellular-based assays. Analytica Chimica Acta, 763, 1-10.

Magan, Naresh, Hope, Russell, Cairns, Victoria, \& Aldred, David. (2003). Post-harvest fungal ecology: impact of fungal growth and mycotoxin accumulation in stored grain Epidemiology of Mycotoxin Producing Fungi (pp. 723-730): Springer.

Mahoney, N.; Molyneux, R.J. Phytochemical inhibition of aflatoxigenicity in Aspergillus flavus by constituents of walnut (Juglans regia). J. Agric. Food Chem. 2004, 52, 1882-1889. [CrossRef] [PubMed]

Mahmoudi R, Golchin A, Hosseinzadeh N, Ghajarbeygi P. Aflatoxin M1 and B1 contaminations in products of animal origin in Iran. J Qazvin Univ Med Sci 2014; 18:49-59.

Marasas, Walter FO. (1996). Fumonisins: history, world-wide occurrence and impact Fumonisins in food (pp. 117): Springer.

Marasas, WF. (2001). Discovery and occurrence of the fumonisins: a historical perspective. Environmental Health Perspectives, 109(Suppl 2), 239.

Miller, J David. (1995). Fungi and mycotoxins in grain: implications for stored product research. Journal of Stored Products Research, 31(1), 1-16.

Minto RE, Townsend CA. Enzymology and molecular biology of aflatoxin biosynthesis. Chemistry Rev 1997; 97 : 
2537- 2555 .

Moreno-Martínez, E, Rivera, A, \& Badillo, M Vázquez. (1998). Effect of fungi and fungicides on the preservation of wheat seed stored with high and low moisture content. Journal of stored products research, 34(4), 231236.

Nesci, A., Passone, M. A., Barra, P., Girardi, N., García, D., \& Etcheverry, M. (2016). Prevention of aflatoxin contamination in stored grains using chemical strategies. Current Opinion in Food Science, 11, 56-60.

Ominski, KH, Marquardt, RR, Sinha, RN, \& Abramson, D. (1994). Ecological aspects of growth and mycotoxin production by storage fungi. Miler, JD and Trenholm, HL (1994). Mycotoxins in grains: Compounds other than aflatoxins. Eagan Press, St. Paul Minnesota, USA, 287-314.

Organization, W. H. (2002). The world health report 2002: reducing risks, promoting healthy life: World Health Organization.

Organization, World Health, \& Cancer, International Agency for Research on. (1993). Some naturally occurring substances: food items and constituents, heterocyclic aromatic amines and mycotoxins. IARC Monographs on the Evaluation of the Carcinogenic Risk of Chemicals to Humans, 56.

Pawa S, Ali S (2006) Boron ameliorates fulminant hepatic failure by counteracting the changes associated with the oxidative stress. Chem-Biol Inter 160:89-98

Peers, F. G.; Gilman, G. A.; Linsell, C. A. Dietary aflatoxins and human liver cancer. A study in Swaziland. Int. J. Cancer 1976, 17, 167-176.

Phillips TD. Dietary clay in the chemoprevention of aflatoxin-induced disease. Toxicological Sciences 1999; 52:118-26.

Pitt, JI. (2000). Toxigenic fungi: which are important? Sabouraudia, 38(Supplement_1), 17-22.

Pitt, John I, Wild, CHRISTOPHER P, Baan, ROBERT A, Gelderblom, WENTZEL CA, Miller, JD, Riley, RT, \& Wu, F. (2012). Improving public health through mycotoxin control: International Agency for Research on Cancer Lyon, France.

Piva G, Pietri A, Carini E. Decontaminations di farina di estrazione di arachide contenente aflatossine mediante trattamento con idrossido di calcio e paraformaldeide. Ann Fat Agric, Catholic University Sacred Hearth (Piacenza), 1985; 25:213-22.

Plummer, S.M.; Holloway, K.A.; Manson, M.M.; Munks, R.J.; Kaptein, A.; Farrow, S.; Howells, L. Inhibition of cyclo-oxygenase 2 expression in colon cells by the chemopreventive agent curcumin involves inhibition of nf-kappab activation via the nik/ikk signalling complex. Oncogene 1999, 18, 6013-6020. [CrossRef] [PubMed]

Prandini A, Tansini G, Sigolo S, Filippi L, Laporta M, Piva G, et al. On the occurrence of aflatoxin M1 in milk and dairy products. Food Chem Toxicol 2009;47:984-91

Probest, "Exposure to aflatoxin B1 in experimental animals and its public health significance," Salud Publica de Mexico, vol. 49, no. 3, pp. 227-235, 2007.

Ravinayagam, V., Jaganathan, R., Panchanadham, S., \& Palanivelu, S. (2012). Potential antioxidant role of tridham in managing oxidative stress against aflatoxin-B1-induced experimental hepatocellular carcinoma. International Journal of Hepatology, 2012.

Salminen S, Nybom S, Meriluoto J, Collado MC, Vesterlund S, El-Nezami H, et al. Interaction of probiotics and pathogens - Benefits to human health? Curr Opin Biotechnol 2010; 21:157-67.

Sharma, S. B., Sayyed, R. Z., Trivedi, M. H., \& Gobi, T. A. (2013). Phosphate solubilizing microbes: sustainable approach for managing phosphorus deficiency in agricultural soils. SpringerPlus, 2(1), 1-14.

Traber MG, Atkinson J. Vitamin E antioxidant and nothing more. Free Radic Biol Med. 2007; 43:4-15.

Turner, P. C., Sylla, A., Diallo, M. S., Castegnaro, J. J., Hall, A. J. and Wild, C. P. 2002. The role of aflatoxins and hepatitis viruses in the etiopathogenesis of hepatocellular carcinoma:Abasis for primary prevention inGuinea-Conakry, West Africa. J. Gastroent. Hep. 17: 441-448.

Udomkun, P., Wiredu, A. N., Nagle, M., Bandyopadhyay, R., Müller, J., \& Vanlauwe, B. (2017). Mycotoxins in Sub-Saharan Africa: Present situation, socio-economic impact, awareness, and outlook. Food Control, 72, $110-122$.

Uriah, N., Ibeh, I. N. and Oluwafemi, F. (2001). A study of the impact of aflatoxin on the human reproduction. Afr. J. Reprod. Health 5: 106-110.

Varga, János, Baranyi, Nikolett, Chandrasekaran, Muthusamy, Vágvölgyi, Csaba, \& Kocsubé, Sándor. (2015). Mycotoxin producers in the Aspergillus genus: An update. Acta Biologica Szegediensis, 59(2), 151-167.

Williams, J.H.; Phillips, T.D.; Jolly, P.E.; Stiles, J.K.; Jolly, C.M.; Aggarwal, D. Human aflatoxicosis in developing countries: A review of toxicology, exposure, potential health consequences, and interventions. Am. J. Clin. Nutr. 2004, 80, 1106-1122. [PubMed]

Wu, Felicia, Groopman, John D, \& Pestka, James J. (2014). Public health impacts of foodborne mycotoxins. Annual review of food science and technology, 5, 351-372. 